\title{
The Incidence of Hypertension and Obesity among Market Women of Child Bearing Age
}

\author{
${ }^{1}$ Sebioniga Lawal M. Yetunde and ${ }^{2}$ Odugbemi Bernice Adebukunola \\ ${ }^{1}$ Department of Public Health Nursing, Ogun State College of Health Technology, Ilese, Ogun State, Nigeria \\ ${ }^{2}$ Community Health Department, Ogun State College of Health Technology, Ogun State Nigeria.
}

\begin{abstract}
Obesity and hypertension are risk factors to a spectrum of cardiovascular diseases. The incidence of hypertension and obesity were assessed among market women of child bearing age. A total of 500 market women were randomly selected from different market site in southwest, Nigeria. Semi-structured questionnaire was used for the data collection, Respondent's Nutritional status was assessed using anthropometric indices and sphygmomanometer was used to assess blood pressure. Findings showed that the mean waist circumference, hip circumference, BMI and waist hip ratio of the women were $85.08 \pm 16.09,101.3 \pm 17.12$, $29.91 \pm 7.16$ and $0.84 \pm 0.10$ respectively. Respondents that were overweight was $21 \%$ while $48 \%$ were obese. About 13\% had low grade hypertension while 6\% were moderately hypertensive. There was significance relationship at $p<0.05$ between nutritional status and waist hip ratio, BMI, and blood pressure of the market women. Effort should be made by all stakeholders in ensuring health education and over nutrition and hypertension among women.
\end{abstract}

Key words: Hypertension, obesity, waist circumference, hip circumference

\section{Introduction}

Obesity is a medical condition in which excess body fat has accumulated to the extent that it may have an adverse effect on health leading to reduced life expectancy and or increased health problems. It is also defined as a body mass index equal or greater than $30 \mathrm{kglm}^{2}$. Overweight can be defined as a body mass index (BMI) equal to or more than $25 \mathrm{~kg} / \mathrm{m}^{2}(1)$. Obesity is rapidly becoming a prominent disease in, developing countries like Nigeria, due to the increase westernization of societies and change in the lifestyle. The causes of obesity is said to be multi-factorial with a combination of genetic an environmental factors. In $2008,35 \%$ of adults aged 20 plus were overweight (BMI $>25 \mathrm{kglm}^{2}$ ) $34 \%$ of men and $35 \%$ of women, in $2008,10 \%$ of men and $14 \%$ of women in the world were obese (BMI $>30 \mathrm{kglm}^{2}$ ) compared with $5 \%$ of men and $8 \%$ of women in 1980 (2). The world Health organization projected that more than 700 million adults worldwide will be obese by 2015. Most market women in urban areas are ignorant of their sedentary life style. They sit in their shops, eat foods that are highly rich in fat and sugar and also in-between meals food consumption are common features (2).

The market women spend a total of 16hours on domestic and market activities, predominantly sedentary activities. This is a form of the market place as an occupational environment that predisposes individual to obesity, mainly due to sedentary lifestyles and enhanced access to food (3). WHO findings in 2005(1) shows that there is a global shift in diet towards increased intake of energy dense foods that are high in fat and sugar but low in vitamins, minerals and other Micronutrients. Therefore, this study assessed the incidence of obesity and overweight among market women.

\section{Methodology}

This study is a cross-sectional to find out the incidence of overweight and obesity among market women in south-western Nigeria. A simple random sampling method was used to enlist market major markets and market women into the study. Prior to the survey, approval to embark on the project was sought from the Department of Nutrition and Dietetics, Rufus Giwa Polytechnic Owo, and the heads of the market groups. Data on anthropometric measurements collected using standard procedures. Descriptive and inferential techniques was used for quantitative data analysis, frequencies, means and percentages were generated using statistical package for social sciences (SPSS version 17)

\section{Table 1: Education Background of the respondent}

\section{Results And Discussion}

The table below shows the respondent level of education in which respondents with secondary school certificate had the highest (36\%) as compared with university with 3\% being the lowest. 
TABLE 1: Education background of the respondent

Education Levels

None

Primary six/ Modern III

Secondary

Post-secondary

University

Total

\begin{tabular}{ll} 
NO & \% \\
60 & 12 \\
170 & 34 \\
180 & 36 \\
75 & 15 \\
15 & 3 \\
$\mathbf{5 0 0}$ & $\mathbf{1 0 0}$ \\
\hline
\end{tabular}

Table 2: Blood Pressure Range

The table below shows the blood pressure range of the respondents in which normal BP has the highest with $79 \%$ and hypotension being the lowest $(2 \%)$

\begin{tabular}{llc} 
Blood Pressure Range & No & \% \\
Hypotension & 2. \\
Normal BP & 395 & 79 \\
Low grade Hypertension & 65 & 13 \\
Moderate grade Hypertension & 30 & 6. \\
Total & $\mathbf{5 0 0}$ & $\mathbf{1 0 0}$ \\
\hline
\end{tabular}

Table 3: Nutrition status according to BMI

The table below shows the nutritional status of the respondents according to BMI, $21 \%$ 0f the respondents were overweight and $48 \%$ were obese.

TABLE 3: NUTRITION STATUS ACCORDING TO BMI

\begin{tabular}{lll}
\hline Nutritional status according to BMI & NO \\
Underweight & 5 \\
Normal weight & 150 & 1 \\
Overweight & 30 \\
Mildly obese & 105 & 21 \\
Moderately obese & 125 & 25 \\
Severely obese & 70 & 14 \\
Total & 45 & 9 \\
\hline
\end{tabular}

Table 4: Nutritional status according to Waist-Hip Ratio

The table below shows the nutritional status of the respondents according to waist hip ratio in which majority $(79 \%)$ were centrally obese.

TABLE 4: NUTRITIONAL STATUS ACCORDING TO WAIST-HIP RATIO

Nutritional status according to Waist Hip Ratio
Normal
Centrally obese
Total

TABLE 5: ANTHROPOMETRIC ASSESSMENT

\begin{tabular}{ll}
\hline Anthropometric parameters & Means + standard Deviation (SD) \\
Weight $(\mathrm{kg})$ & $74.91 \pm 16.249$ \\
Height $(\mathrm{m})$ & $1.59 \pm 0.78$ \\
MUAC $(\mathrm{cm})$ & $31.84 \pm 9.07$ \\
Waist circumference $(\mathrm{cm})$ & $85.08 \pm 16.09$ \\
Hip circumference $(\mathrm{cm})$ & $101.3 \pm 17.12$ \\
BMI $(\mathrm{kg} / \mathrm{m} 2)$ & $29.91 \pm 7.16$ \\
Waist HIP Ratio & $0.84 \pm 0.10$ \\
\hline
\end{tabular}

\section{Discussion}

Table 1 shows the market used for the study $50 \%$ being the highest percentage was from "shasha" market because it is the most visited and big market in Akure North. Oba-Ile market was next with $30 \%$ also a main market in Akure North spent every five days. Ilu-Abo market was the last market with $20 \%$ being a neighborhood market.

Education status of the respondents determines their occupation as market women, $12 \%$ were not educated, while $36 \%$ attended secondary school. Studies have shown that there was an increase of obesity among non-educated and primary women compared with women with secondary education or high with low risk of obesity. (5). Occupation of the women affected their food intake and frequency of feeding. This confirms 
reports that heavy workload for women might leads to poorer diet not only for their children and other members of the family, but also for the women themselves (6)

The anthropometric assessments showed most of the women were overweight and obese $(21 \%$ and $48 \%$ respectively), which made them have more than the normal or desirable BMI. This result agreed with the findings of $(7,8)$ which reported high prevalence of overweight and obesity in their studies $(10 \%$ and $21 \%$ respectively). But disagreed with the findings of a study on Nutritional status of women of reproductive age in rural Bangeldash where most of the women were found to fall within the normal range of BMI (9) The prevalence of overweight and obesity among market women may be as a result of high fatty street food, sugar and starchy food from vendors, which is contributing to increasing prevalence of obesity and overweight. This result agreed with the work of (10) who reported that most of the market women sit I their shops, eat food that are highly rich in fat and sugars and also in high calorie diet.

The study showed that $19 \%$ of the respondents were hypertensive, this is because hypertension is more common in obese than normal weight. This study agreed with earlier studies $(11,12)$ that reported that hypertension is approximately three times more common in obese than normal weight person). This relationship maybe cause- and -effect in that when weight increases, so does blood pressure (13).

\section{References}

[1]. World Health Organization; (2005) Bulletin of the World Health Organization on obesity and overweight 89; 7:579-86

[2]. World Health Organization; (2011). Obesity; preventing and managing the global epidemic. Report of WHO consultation on obesity, Geneva: 1997 P.1-276

[3]. Ajani J.A (2003). Prevalence of hypertension and diabetes mellitus in obese market men in Ibadan. Nutrition survey $2^{\text {nd }}$ edit (2):67-98.

[4]. Himes, A.R., (1991): Effects of Overweight and Obesity on Health. Ann Intern Med10; 55-72.

[5]. Abdulbari B. (2006). Prevalence of obesity, overweight, and underweight in Qatari adolescents. Food Nutr Bull , 27: 39-45

[6]. Holmboe-Ottesen G, (1993) Preliminary results from field surveys on nutritional and socio- economic conditions in the Kirama Oya river basin. In: Progress report to NORAD. Oslo: Institute for Nutrition Research.

[7]. Abubakari AR, Lauder W, Agyemang C, Jones M, Kirk A, Bhopal RS; (2008). Prevalence and time trends in obesity among adult west Africa population Obes Rev 9(4): 297-311.

[8]. Wolfe A.W., (2010). Rescue of Obesity-Induced Infertility in female mice due to a pituitary-specific knockout of insulin receptor. European journal on nutrition 53: 765-769.

[9]. Rahman M., Abbey B., and Benson (2009). Accuracy of current body mass index obesity classification for white, black and Hispanic reproductive-age women. Pages 58:1329- 1337

[10]. Popkin B .M, (2012). The nutrition transition and obesity in the developing World J. Nutr 131; 5871-3.

[11]. World Health Organization; (2011). Obesity; preventing and managing the global epidemic. Report of WHO consultation on obesity, Geneva: 1997 P.1-276

[12]. Van Italie (1985). Health implication of obesity: an NIH consensus development conference. Pages 9(3): 155-170

[13]. Messerli H. (1995), Obesity and Hypertension, Hearth failure and coronary heart disease: Risk factor, paradox, and Recommendations for weight loss. Pages 9(3): 124-132. 